\title{
Subcutaneous apomorphine infusion in Parkinson's disease: does it have a role?
}

\author{
Khulood A. Muhiddin, Mary T. Roche and Vaughan R. Pearce
}

Department of Care of the Elderly, Royal Devon and Exeter Hospital (Heavitree), Gladstone Road, Exeter EXI 2ED, UK

\begin{abstract}
Summary: Apomorphine is a potent dopamine agonist at both D1 and D2 receptors and has been used successfully for treating the 'on/off' phenomenon in Parkinson's disease. We report our experience with apomorphine in treating the 'on/ofr' phenomenon in L-dopa responsive idiopathic Parkinson's disease. Thirteen such patients were commenced on apomorphine infusions. Their mean age was 69 (range 53-80) years and the mean duration of the disease was 15 (range 6-28) years. The clinical response to apomorphine was good in four patients, fair in two, unchanged in five and worse in two. Activities of daily living improved in six, were unchanged in five and worse in two. When the response was poor or showed no change, apomorphine was discontinued. In addition, apomorphine was also discontinued in three patients who had had a fair/good response but suffered side effects of hallucinations, delusions and psychosis, lack of cooperation or found the pump inconvenient. Apomorphine was continued in only three patients out of 13.
\end{abstract}

\section{Introduction}

In Parkinson's disease, the striatal dopamine content is decreased in proportion to the degree of degeneration of dopamine-containing neurons in the substantia nigra. ${ }^{1}$ L-Dopa therapy depends on the capacity of the remaining neurons to synthesize dopamine in sufficient quantities to stimulate the striatal dopamine receptors. ${ }^{2,3}$ The majority of patients treated with oral L-dopa for more than 3-5 years will develop fluctuation in clinical response and drug-induced dyskinesias which can be just as disabling as the disease itself. ${ }^{4,5}$ In some patients oscillations in motor response were found to be related to the fluctuation in L-dopa plasma levels that accompany oral treatment ${ }^{6}$ and keeping a constant blood level of L-dopa by a continuous intravenous infusion can eliminate some motor fluctuations. ${ }^{7}$ Dopamine agonists such as lisuride and apomorphine have also been found to be effective in treating Parkinson's disease when administered in a continuous subcutaneous infusion. ${ }^{8,9}$

Apomorphine was the first dopamine agonist found to have anti-parkinsonian properties. ${ }^{10}$ However, it was only successfully used in treating the 'on/off' phenomenon when it was delivered by a mini-pump as a continuous subcutaneous infusion or by a pen-injector for intermittent use. ${ }^{9}$ In this article we present our experience with apomorphine.

Correspondence: K.A. Muhiddin, Ph.D. (Lond.), M.R.C.P.(UK).

Accepted: 20 December 1993

\section{Materials and methods}

We studied 13 patients with L-dopa-responsive Parkinson's disease (mean age 69 years, range 53-80; and mean duration of disease 15 years, range 6-28) who were admitted to hospital, between July 1988 and July 1991, to initiate apomorphine therapy by subcutaneous infusion using a Grasby MS26 pump and following the regime of Stibe et al. ${ }^{9}$ Apomorphine hydrochloride (Macfarlan Smith of Edinburgh) was prepared in the North Middlesex Hospital. The indication for such treatment was fluctuations in the clinical symptoms which appeared unrelated to the optimal timing of medication ('on/off' phenomenon). The dose of apomorphine varied between 1.7 and $6.0 \mathrm{mg} /$ hour, while the duration of the infusion ranged between 12 and 24 hours a day starting with a dose of $10 \mathrm{mg} /$ day to be increased daily, following daily assessment, by $10 \mathrm{mg}$ up to $70 \mathrm{mg} /$ day, at which point if no response was elicited the trial of apomorphine was pronounced failed. However, the total dose of apomorphine could be increased further if the above mentioned protocol showed partial response. The clinical response was judged by on/off charts, ${ }^{9}$ while the change in active daily living (ADL) was assessed collectively by nursing, physiotherapy and occupational therapy teams. Patients who responded successfully to apomorphine continued to administer the drug subcutaneously via a pump. 


\section{Results}

The clinical response to apomorphine was good in four patients, fair in two, no change in five and worse in two. ADL improved in six, was unchanged in five and worse in two (Table I). When the response was poor or showed no change, apomorphine was discontinued. In addition, apomorphine was also discontinued in three patients who had had a fair/good response to apomorphine; this was due to side effects of hallucination, delusions and psychosis, lack of patient's cooperation and the inconvenience of the pump. Apomorphine was continued in only three patients out of 13 (Table I). These three patients gained appreciable benefit from apomorphine; one of them received the treatment for 28 months until he died of a cerebrovascular event, whilst the other two patients have been receiving apomorphine for 24 and 22 months so far. One recipient has, on occasions, been bothered by temporary lumps at the site of infusion, which is a recognized problem, but these have not necessitated cessation of treatment.

It is worth noting that all anti-parkinsonian drugs were withdrawn in two cases. One when the prognosis was poor and the other appearing to become unresponsive to all anti-parkinsonian medication though the diagnosis of Parkinson's disease was confirmed at postmortem.

\section{Discussion}

Fluctuation in the clinical symptoms of Parkinson's disease is one of the characteristics of the treatment of disease. These fluctuations include end of dose effect, early morning akinesia, dyskinesias and the 'on/off' phenomenon. Although the long-term therapeutic effects of L-dopa are fairly constant in some parkinsonian patients, late in the treatment others develop the 'on/off' phenomenon with or without the emergence of dyskinesia. ${ }^{11}$ The incidence of the disabling fluctuations in motor performance occur in more than $50 \%$ of parkinsonian patients after 5 years of L-dopa treatment. ${ }^{4,5}$ The underlying pathophysiology is not entirely clear with several pharmacokinetic and pharmacodynamic mechanisms having been proposed. Factors include delayed gastric emptying, incomplete absorption from the gut, and competition with large amino acids in crossing the blood-brain barrier. It has been shown that meals reduced plasma levels of L-dopa by about $29 \%$ and delayed the absorption by 34 minutes. ${ }^{12}$ Variable absorption of L-dopa could be overcome by intravenous infusion of L-dopa. However, pharmacodynamic mechanisms seem to have a role in the unpredictable fluctuations. Denervated dopamine receptors develop a dopamine receptor supersensitivity, leading to dyskinesia when dopamine is given. Apomorphine, like lisuride and pergolide, is a potent dopamine agonist at both $\mathrm{D} 1$ and $\mathrm{D} 2$ receptors. It has been found that D2 receptor stimulation is important in mediating the beneficial effects of the dopamine agonists. However, recent studies have shown that D1 stimulation is required before $\mathrm{D} 2$ activation can be revealed, and therefore simultaneous activation of both D1 and D2 receptors is necessary to produce any physiological and behavioural

Table I Response to apomorphine in 132 parkinsonian patients

\begin{tabular}{|c|c|c|c|c|}
\hline $\begin{array}{l}\text { Patient } \\
\text { number }\end{array}$ & \multicolumn{2}{|c|}{ Apomorphine } & Change in $A D L$ & Treatment plan (continued/discontinued) \\
\hline 1 & $70 \mathrm{mg} / 24$ hours & Fair & $\begin{array}{l}\text { Marginal } \\
\text { improvement }\end{array}$ & $\begin{array}{l}\text { Discontinued (due to psychotic side effect } \\
\text { and lack of patient's cooperation) }\end{array}$ \\
\hline 2 & $4 \mathrm{mg} / 1$ hour & Worse & Worse & $\begin{array}{l}\text { Discontinued (due to dyskinesia, choriform } \\
\text { movements and lack of response) }\end{array}$ \\
\hline 3 & $90 \mathrm{mg} / 15$ hours & Good & Improved & $\begin{array}{l}\text { Continued (for } 28 \text { months until he died following } \\
\text { a stroke) }\end{array}$ \\
\hline 4 & $20 \mathrm{mg} / 12$ hours & Worse & Worse & Discontinued (due to side effect of confusion) \\
\hline 5 & $120 \mathrm{mg} / 12$ hours & No change & No change & $\begin{array}{l}\text { Discontinued (due to lack of response and a } \\
\text { side effect of twitching) }\end{array}$ \\
\hline 6 & $70 \mathrm{mg} / 24$ hours & No change & No change & Discontinued (due to lack of response) \\
\hline 7 & $70 \mathrm{mg} / 12$ hours & No change & No change & Discontinued (due to lack of response) \\
\hline 8 & $50 \mathrm{mg} / 15$ hours & Good & Improved & $\begin{array}{l}\text { Discontinued (due to minimal subjective } \\
\text { improvement and the inconvenience of the pump) }\end{array}$ \\
\hline 9 & $130 \mathrm{mg} / 24$ hours & Good & Improved & Continued (for 24 months to date) \\
\hline 10 & $70 \mathrm{mg} / 15$ hours & Fair & Improved & $\begin{array}{l}\text { Discontinued (due to side effects of } \\
\text { hallucinations and delusions) }\end{array}$ \\
\hline 11 & $60 \mathrm{mg} / 12$ hours & No change & No change & Discontinued (due to lack of response) \\
\hline 12 & $70 \mathrm{mg} / 24$ hours & No change & No change & $\begin{array}{l}\text { Discontinued (due to lack of response, } \\
\text { and no recovery from stroke) }\end{array}$ \\
\hline 13 & $140 \mathrm{mg} / 24$ hours & Good & Improved & Continued (for 22 months to date) \\
\hline
\end{tabular}


effects. ${ }^{13}$ It follows that non-selective dopamine agonists such as apomorphine may be superior to a more selective (D2) agonist such as bromocriptine.

Out of the 13 patients reviewed, only six patients showed some improvement in the 'off' periods and ADL when commenced on subcutaneous apomorphine. However, apomorphine had to be discontinued in three of these six responders leaving only three patients who continued with this treatment long term. These results are not in agreement with other investigators who studied the therapeutic potential of apomorphine. Frankel and colleagues in $1990^{14}$ published their experience in using apomorphine in a total of 57 parkinsonian patients (32 received intermittent dosages and 25 had continuous subcutaneous infusion); there were only eight who failed to respond to apomorphine due to side effects and difficulty in handling the pump. Similar encouraging results were reported using penject or mini-pump to administer subcutaneous injections of apomorphine. The sizes of these studies were 19 patients, ${ }^{9}$ nine patients ${ }^{15}$ and seven patients. ${ }^{16}$ On the other hand, other investigators found a less rewarding outcome from using apomorphine. Obeso and colleagues in $1987^{17}$ found that apomorphine infusion abolished 'off' periods in the four patients with end-of-dose deterioration but did not produce any stable response in four of the five patients with 'on/off' fluctuations. Moreover, Ruggieri and co-workers in $1989^{18}$ found the apomorphine had to be discon-

\section{References}

1. Bernheimer, J., Birkmayer, W. \& Hornykiewicz, O. Brain dopamine and the syndromes of Parkinson and Huntington. $J$ Neurol Sci 1973, 20: 415-455.

2. Calne, D.B., Williams, A.C. \& Neophytides, A. Long-term treatment of Parkinsonism with bromocriptine. Lancet 1978, i: $735-738$.

3. Davidson, L., Lloyd, K. \& Dankova, J. L-Dopa treatment in Parkinson's disease: effect of dopamine and related substance in discrete brain regions. Experientia 1971, 27: 1048-1049.

4. Shaw, K.M., Lees, A.J. \& Stern, G.M. The impact of treatment with levodopa in Parkinson's disease. $Q \mathrm{~J} \mathrm{Med}$ 1980, 49: 283-293.

5. Marsden, C.D. \& Parkes, J.D. 'On-off' effects in patients with Parkinson's disease on chronic levodopa therapy. Lancet 1976, i: 292-296.

6. Tolosa, E.S., Martin, W.E., Cohen, H.P. \& Jacobson, R.S. Patterns of clinical response and plasma dopa levels in Parkinson's disease. Neurology 1975, 25: 177-183.

7. Hardie, R.J., Lees, A.J. \& Stern, G.M. On-off fluctuations in Parkinson disease. Brain 1984, 107: 487-506.

8. Obeso, J.A., Luquin, M.R. \& Martinez-Lage, J.M. Lisuride infusion pump: a devise for the treatment of fluctuations in Parkinson's disease. Lancet 1986, i: 467-470.

9. Stibe, C.M.H., Lees, A.J., Kempster, P.A. \& Stern, G.M. Subcutaneous apomorphine in Parkinsonian on-off oscillations. Lancet 1988, i: 403-406.

10. Schwab, R.S., Amador, L.V.\& Lettvin, J.Y. Apomorphine in Parkinson's disease. Trans Am Neurol Assoc 1951, 76: 251-253. tinued in five out of the six patients due to side effects (four of whom had neuropsychiatric adverse effects).

The dosage used in our group of patients was comparable to that used in other studies and the infusion was always prepared in the hospital pharmacy minimizing the risk of variability in the final concentration of the drug. In addition, the final proportion of various optical isomers of apomorphine in the administered infusion is within the acceptable pharmacopoeial limits.

For clinicians planning to introduce continuous subcutaneous infusion of apomorphine in treating the 'on/off' phenomenon, our experience would suggest that a smaller proportion of patients will both benefit from and tolerate the treatment than some of the published work would suggest. Nevertheless, this treatment, when successful, enables an otherwise severely disabling aspect of late Parkinson's disease to be overcome and the patient to remain at home living independently longer than would otherwise be possible.

We could identify no clinical features which could help in identifying patients who are more likely to respond successfully.

\section{Acknowledgement}

We would like to thank Karina Mulcock, community pharmacist, and the Parkinson's Disease Society.

11. Cotzias, G.C., Papavasiliou, P.S. \& Gellene, R. Modification of Parkinsonism - chronic treatment with L-dopa. $N$ Engl $J$ Med 1989, 280: 337-345.

12. Nutt, J.G., Woodward, W.R., Hammerstad, J.P., Carter, J.H. \& Anderson, J.L. The on-off phenomenon in Parkinson's disease. Relation to levodopa absorption and transport. N Engl J Med 1984, 310: 483-488.

13. Walter, J.R., Bergstrom, D.A., Carlson, J.H., Chase, T.N. \& Braun, A.R. D1 dopamine receptor activation required for postsynaptic expression of D2 agonist effects. Science 1987, 236: 719-722.

14. Frankel, J.P., Lees, A.J., Kempster, P.A. \& Stern, G.M. Subcutaneous apomorphine in the treatment of Parkinson's disease. J Neurol Neurosurg Psychiatry 1990, 53: 96-101.

15. Chaudhuri, K.R., Critchley, P., Abbott, R.J., Pye, I.F. \& Millac, P.A.H. Subcutaneous apomorphine for on-off oscillations in Parkinson's disease. Lancet 1988, ii: 1260.

16. Poewe, W.H., Kleedorfer, B., Gerstenbrand, F. \& Oertel, W. Subcutaneous apomorphine in Parkinson's disease. Lancet 1988, i: 943.

17. Obeso, J.A., Grandas, F., Vaamonde, J., Luquin, M.R. \& Martinez-Lage, J.M. Apomorphine infusion for motor fluctuations in Parkinson's disease. Lancet 1987, i: 1376-1377.

18. Ruggieri, S., Stocchi, F., Carta, A. \& Agnoli, A. Side effects of subcutaneous apomorphine in Parkinson's disease. Lancet 1989 , i: 566 . 